\title{
Seroprevalence and Risk Factors of Toxoplasma gondii Infection among Domestic Ruminants in East Hararghe Zone of Oromia Region, Ethiopia
}

\author{
Berhanu Tilahun ${ }^{D},{ }^{1}$ Yacob Hailu Tolossa, ${ }^{2}$ Getachew Tilahun, ${ }^{3}$ \\ Hagos Ashenafi, ${ }^{2}$ and Shihun Shimelis ${ }^{1}$ \\ ${ }^{1}$ Department of Parasitology, College of Veterinary Medicine, Haramaya University, P.O. Box 138 Dire Dawa, Ethiopia \\ ${ }^{2}$ Department of Pathology and Parasitology, College of Veterinary Medicine and Agriculture, Addis Ababa University, \\ P.O. Box 34, Bishoftu, Ethiopia \\ ${ }^{3}$ Aklilu Lemma Institute of Pathobiology, Addis Ababa University, P.O. Box 1176, Addis Ababa, Ethiopia
}

Correspondence should be addressed to Berhanu Tilahun; btilahun11@gmail.com

Received 18 October 2017; Revised 9 March 2018; Accepted 4 April 2018; Published 20 May 2018

Academic Editor: Francesca Mancianti

Copyright (C) 2018 Berhanu Tilahun et al. This is an open access article distributed under the Creative Commons Attribution License, which permits unrestricted use, distribution, and reproduction in any medium, provided the original work is properly cited.

A cross-sectional study was carried out from July 2011 to September 2013 to assess the seroprevalence and identify risk factors of Toxoplasma gondii infection in domestic ruminants of East Hararghe zone of Oromia region, Ethiopia. Sera of 1360 domestic ruminants were analyzed for the presence of anti-T. gondii IgG antibodies using the indirect enzyme-linked immunosorbent assay (iELISA). Additionally, the owners were also interviewed using a structured questionnaire to identify the potential risk factors of $T$. gondii infection. Overall, the prevalence of T. gondii infection in domestic ruminants was $22.2 \%(302 / 1360)$. The seroprevalence in sheep, goats, cattle, and camels was $33.7 \%, 27.6 \%, 10.7 \%$, and $14.4 \%$, respectively. District, species, sex, age, and water source were identified as risk factors for T. gondii infection. Increased seropositivity was observed in females $(\mathrm{OR}=2.63)$ and also with the use of pond $(\mathrm{OR}=4.25)$ and pipe $(\mathrm{OR}=9.57)$ water sources in sheep; age $>1$ year old $(\mathrm{OR}=3.45)$ and with drinking from pond $(\mathrm{OR}$ $=6.03)$ and pipe $(\mathrm{OR}=11.61)$ water sources in goats; with the use of pond $(\mathrm{OR}=5.60)$ and pipe $(\mathrm{OR}=10.68)$ water sources in cattle; and in $>4$-year-old camels $(\mathrm{OR}=2.49)$. In conclusion, $T$. gondii infection is common and widespread among the domestic ruminants of the study area, indicating the potential transmission to humans from these animals when they are used as a source of food. Hence, it is crucial to raise awareness of the people about $T$. gondii infection and conduct further study to explore the impact of the disease on food animal production.

\section{Introduction}

Toxoplasma gondii is an obligate intracellular protozoan parasite with worldwide distribution which can infect all warm blooded animals and man. Most animals and man serve as intermediate hosts, while domestic cats and wild felids are definitive hosts that have an important role in the transmission of T. gondii infection by shedding oocysts to the environment. Animals and humans can acquire T. gondii infection by ingesting feed and water contaminated with cats' faeces containing infective oocysts and animal tissues with viable cysts of $T$. gondii and congenitally [1].
Toxoplasmosis is an economically important disease of livestock, causing abortion, stillbirth, fetal malformation, preterm deliveries, and neonatal death predominantly in sheep and goats infected by T. gondii, subsequently creating a potential challenge to the small ruminant industry worldwide [2]. Food animals infected with T. gondii pose a risk for the public, since consumption of raw or undercooked meat from such animals can facilitate zoonotic transmission. Moreover, T. gondii can be congenitally transmitted to the foetus during pregnancy $[1,3,4]$.

Several reports have indicated a great variation on the seroprevalence of T. gondii infection in domestic ruminants 
across the world and it ranges from $3 \%$ to $92 \%$ in sheep $[3,5]$, from $5 \%$ to $77 \%$ in goats $[3,6,7]$, and from $0 \%$ to $99 \%$ in cattle [8]. In Africa, the reported seroprevalence in animals varied between $3.6 \%$ and $57.5 \%$ [9-13].

The estimated domestic ruminant population of Ethiopia in millions is sheep (27.35), goats (28.16), cattle (55.03), and camels (1.10) [14]. These large populations of domestic ruminants are mostly raised for milk, meat production, and breeding purpose. The seroprevalence of T. gondii infection in Ethiopia ranges from $22.9 \%$ to $54.7 \%$ in sheep and from $11.6 \%$ to $74.8 \%$ in goats [15-20]. Aside from that, the only report found on the seroprevalence T. gondii infection in cattle was that of $6.6 \%$ in Central Ethiopia [16]. Nonetheless, to date, there is no report from East Hararghe zone. Therefore, this study was carried out to bridge this information gap with the objectives of determining the seroprevalence and identifying the potential risk factors of T. gondii infection in domestic ruminants of East Hararghe zone.

\section{Materials and Methods}

2.1. Study Area. The study was conducted in three selected districts of East Hararghe zone of Oromia region, Ethiopia. The districts were found at an altitude ranging from 950 to 2950 meters above sea level (masl). Accordingly, Gursum district is located at $9^{\circ} 7^{\prime}-32^{\circ} 14^{\prime} \mathrm{N}$ latitude and $42^{\circ} 17^{\prime}-42^{\circ} 38^{\prime} \mathrm{E}$ longitude with an altitude range of 1200-2950 masl; Babille district is located at $8^{\circ} 9^{\prime}-9^{\circ} 23^{\prime} \mathrm{N}$ latitude and $41^{\circ} 16^{\prime}-41^{\circ} 46^{\prime} \mathrm{E}$ longitude with an altitude ranging from 950 to 2000 masl; and Haramaya district is located at $9^{\circ} 9^{\prime}-9^{\circ} 32^{\prime} \mathrm{N}$ latitude and $41^{\circ} 50^{\prime}-42^{\circ} 05^{\prime} \mathrm{E}$ longitude with an altitude ranging from 1600 to 2140 masl. The districts are inhabited mainly by the "Oromo" tribe. Crop production and livestock rearing are the main economic activities in the rural areas, while small-scale trade is practiced in urban areas. Sorghum, maize, groundnut, "chat" ("khat"), and wheat are the main crops produced [21].

2.2. Study Animals and Design. The study animals comprised indigenous sheep, goats, cattle, and camels kept under extensive grazing system. Districts were selected purposively depending on their accessibility. Within the districts, 38 "kebeles" (lowest administrative units) from both rural and urban areas were identified by simple random sampling from the lists obtained from the respective district administrations.

The sample size was determined using a method recommended by Thrusfield [22]. A total of 1360 animals (sheep $=332$, goats $=410$, cattle $=326$, and camels $=292$ ) were sampled based on expected prevalence of $57.4 \%$ for sheep and $26 \%$ for goats [18] and 50\% for both cattle and camels at 5\% absolute precision and 95\% confidence level. The sample size was allocated proportionally to the selected study districts. Individual sample units were identified systematically at night resting places, grazing areas, and watering points. Only sheep, goats, and cattle above six months of age and camels above two years of age were included in the study.

2.3. Blood Samples Collection and Serology. A total of 1360 animal sera were collected and analyzed from July 2011 to September 2013. Approximately 5-10 $\mathrm{ml}$ of blood was drawn from the jugular vein using plain vacutainer tubes and kept overnight at room temperature to clot for serum separation. Aliquots of sera were obtained by centrifugation at 3000 revolutions per minute for $10 \mathrm{~min}$ and the sera were transported to the parasitology laboratory of College of Veterinary Medicine and Agriculture at Bishoftu (Debre Zeyit) in ice box and stored at $-20^{\circ} \mathrm{C}$ until they were tested.

All sera were tested for anti-T. gondii IgG antibodies using indirect ELISA multispecies diagnostic kit (ID VET Innovative Diagnostic, ID Screen, Montpellier, France). On each working day, only the required amount of antigen and sera were thawed prior to serological testing. The preparation of the reagents and the iELISA test were performed based on the manufacturer's recommendation at the National Animal Health Diagnostic and Investigation Center (NAHDIC) Sebeta, Ethiopia. Positive and negative controls were included in each test and an animal was considered to be infected when the serum presented an OD $2 \geq 50 \%$ with ELISA. Herds or flocks were considered as T. gondii seropositive, when at least one animal was tested positive.

2.4. Questionnaire Survey. 100 verbally consented owners of domestic ruminants whose herds and flocks were involved in the survey were interviewed using a structured closeended questionnaire. The gathered information included the demographic characteristics of the animals such as age, sex, breed, herd size, and physiological status of the animals and their husbandry including house types, feed storage facilities, grazing types, and water sources as well as cats holding and the presence of feral cats in the vicinity (variables obtained from literatures).

2.5. Statistical Analysis. The data were analyzed using STATA version 11.0 for MA Windows (Stata Corp., College Station, USA). The data were categorized to make the analysis easy. Accordingly, sheep and goats were classified in two groups as $\leq 1$ year and $>1$ year old, cattle into three groups as $\leq 1$ year, $>1-5$ years, and $>5$ years old, and camels into two groups, $\leq 4$ years and $>4$ years old. The flock/herd size for sheep, goats, and cattle was considered as small ( $<10$ animals) or large ( $\geq 10$ animals), while for camels it was considered as small ( $\leq 34$ animals) or large ( $>34$ animals). Type of housing with total confinement is categorized as pen for sheep and goats and barn for cattle, while it is classed as fence for those with access to the outside. Water source was classified as mixed (river, stream, pond, and well), pond, and pipe water (except camels). Species seroprevalence and the association of risk factors as independent categorical variable with $T$. gondii seropositivity were analyzed by the chisquare test $\left(\chi^{2}\right)$. Logistic regression analysis was performed to measure the strength of association between the potential risk factors and T. gondii seropositivity. Noncollinear variables with values of $P<0.20$ in univariable analysis at $95 \%$ confidence level were entered into multivariable logistic regression model. The level of statistical significance was set as $P<0.05$. 
TABLE 1: Seroprevalence of T. gondii infection in domestic ruminants.

\begin{tabular}{|c|c|c|c|c|c|c|c|c|}
\hline \multirow{2}{*}{ Species } & \multicolumn{4}{|c|}{ Animal level } & \multicolumn{4}{|c|}{ Herd/flock level } \\
\hline & $N$ & No. of positive & Percentage (\%) & $95 \% \mathrm{CI}$ & $N^{*}$ & No. of positive & Percentage (\%) & $95 \% \mathrm{CI}$ \\
\hline Sheep & 332 & 112 & 33.73 & $28.66-39.10$ & 102 & 62 & 60.78 & $50.62-70.31$ \\
\hline Goats & 410 & 113 & 27.56 & $23.29-32.16$ & 120 & 67 & 55.83 & $46.48-64.89$ \\
\hline Cattle & 326 & 35 & 10.74 & $7.59-14.61$ & 82 & 19 & 23.17 & $14.56-33.80$ \\
\hline Camels & 292 & 42 & 14.38 & 10.57-18.94 & 47 & 25 & 53.19 & $38.08-67.89$ \\
\hline Total & 1360 & 302 & 22.2 & $20.02-24.51$ & 351 & 173 & 49.29 & $43.94-54.65$ \\
\hline
\end{tabular}

$N$ : number of animals tested; No.: number; $N^{*}$ : number of herds/flocks tested; CI: confidence interval (CI).

TABLE 2: Analysis of risk factors related to T. gondii seropositivity in sheep at animal level $(n=332)$.

\begin{tabular}{|c|c|c|c|c|c|c|}
\hline Variables & Category & Number tested & Positive (\%) & Crude OR (95\% CI) & Adjusted OR (95\% CI) & $P$ value \\
\hline \multirow{3}{*}{ District } & Haramaya & 95 & $25(26.3)$ & 1.00 (ref.) & 1.00 (ref.) & \\
\hline & Gursum & 143 & $44(30.8)$ & $1.24(0.70-2.22)$ & $0.69(0.35-1.34)$ & 0.270 \\
\hline & Babille & 94 & $43(45.7)$ & $2.36(1.28-4.35)$ & $0.95(0.46-1.94)$ & 0.881 \\
\hline \multirow{2}{*}{ Environment } & Rural & 253 & $58(22.9)$ & 1.00 (ref.) & - & - \\
\hline & Urban & 79 & $54(68.4)$ & $7.26(4.16-12.68)$ & - & - \\
\hline \multirow{2}{*}{ Sex } & Male & 68 & $11(16.2)$ & 1.00 (ref.) & 1.00 (ref.) & - \\
\hline & Female & 264 & $101(38.3)$ & $3.21(1.61-6.41)$ & $2.63(1.18-5.88)$ & $0.019^{*}$ \\
\hline \multirow{2}{*}{ Age } & $\leq 1$ year & 39 & $9(23.1)$ & 1.00 (ref.) & 1.00 (ref.) & \\
\hline & $>1$ year & 293 & $103(35.2)$ & $1.81(0.83-3.95)$ & $1.15(0.45-2.91)$ & 0.772 \\
\hline \multirow{2}{*}{ Flock size } & Small & 270 & $89(33.0)$ & 1.00 (ref.) & - & - \\
\hline & Large & 62 & $23(37.1)$ & $1.20(0.68-2.13)$ & - & - \\
\hline \multirow{2}{*}{ Cats contact } & No & 207 & $62(30.0)$ & 1.00 (ref.) & 1.00 (ref.) & - \\
\hline & Yes & 125 & $50(40.0)$ & $1.56(0.98-2.48)$ & $1.28(0.74-2.20)$ & 0.371 \\
\hline \multirow{3}{*}{ Water source } & Mixed $^{\dagger}$ & 198 & $34(17.2)$ & 1.00 (ref.) & 1.00 (ref.) & \\
\hline & Pond $^{\ddagger}$ & 55 & $24(43.6)$ & $3.73(1.95-7.14)$ & $4.25(2.15-8.38)$ & $<0.001^{*}$ \\
\hline & Pipe water & 79 & $54(68.4)$ & $10.42(5.71-19.00)$ & $9.57(5.00-18.33)$ & $<0.001^{*}$ \\
\hline \multirow{3}{*}{ House type } & Pen & 24 & $3(12.5)$ & 1.00 (ref.) & - & - \\
\hline & Both & 207 & $48(23.2)$ & $2.11(0.60-7.39)$ & - & - \\
\hline & Fence & 101 & $61(60.4)$ & $10.68(2.99-38.15)$ & - & - \\
\hline
\end{tabular}

Mixed $^{\dagger}$ : river, stream water, and well; Pond ${ }^{\ddagger}$ : stagnant water; OR: odds ratio; CI: confidence interval. * Significant.

\section{Results}

3.1. Serological Findings. Out of 1360 sera of domestic ruminants tested, the presence of anti-T. gondii IgG antibodies was detected in 302 (22.2\%, 95\% CI: $20.0 \%-24.5 \%)$ of them that belonged to 173 (49.29\%, 95\% CI: 43.94\%-54.65\%) herds or flocks. The highest seroprevalence of infection was observed in sheep (33.7\%) and the lowest was in cattle (10.7\%). The distribution of T. gondii infection among domestic ruminants is presented in Table 1. T. gondii infection was detected in 32 out of the 38 (84.2\%) farm areas/ "kebeles" included in the study.

In a univariable analysis, goats had high risk of $T$. gondii infection $(\mathrm{OR}=0.75,95 \% \mathrm{CI}: 0.55-1.02, P=0.069)$ comparable with that of sheep, whereas cattle $(\mathrm{OR}=0.24$, 95\% CI: $0.16-0.36, P<0.001)$ and camel $(\mathrm{OR}=0.33,95 \%$ CI: $0.22-0.49, P<0.001)$ were at low risk.

3.1.1. Sheep. A multivariable logistic regression analysis showed that sex of the animal and water source were risk factors for increased seroprevalence. A higher risk of T. gondii infection occurred in females $(\mathrm{OR}=2.63,95 \% \mathrm{CI}$ : $1.18-5.88$, $P=0.019)$ than in males in those given pipe water $(\mathrm{OR}=$ 9.57, 95\% CI: $5.00-18.33, P<0.001)$ and pond water $(\mathrm{OR}=$ 4.25 , 95\% CI: $2.15-8.38, P<0.001)$ compared with those that drank from a mixed water source (Table 2). But the variables district, age, and cats contact were insignificant $(P>0.05)$. Nonetheless, relatively higher seroprevalence was observed in sheep from Babille district (45.7\%) than from Gursum $(30.8 \%)$ and Haramaya $(26.3 \%)$, in $>1$ year old $(35.2 \%)$ than in $\leq 1$ year old $(23.1 \%)$, and in those having contact with cats $(40.0 \%)$ than in those not in contact $(30.0 \%)$.

3.1.2. Goats. District, age, and water sources were identified as risk factors for T. gondii infection. An increased risk of infection occurred in goats $>1$ year old $(\mathrm{OR}=3.45,95 \% \mathrm{CI}$ : 1.34-8.90, $P=0.010)$ compared to $\leq 1$ year and in those given pipe ( $\mathrm{OR}=11.61,95 \% \mathrm{CI}: 4.35-30.95, P<0.001)$ and pond water $(\mathrm{OR}=6.03,95 \% \mathrm{CI}: 2.42-15.05, P<0.001)$ than 
TABLE 3: Logistic regression analysis of risk factors with T. gondii seropositivity in goats at animal level $(n=410)$.

\begin{tabular}{|c|c|c|c|c|c|c|}
\hline Variables & Category & Number tested & Positive (\%) & Crude OR $(95 \% \mathrm{CI})$ & Adjusted OR (95\% CI) & $P$ value \\
\hline \multirow{3}{*}{ District } & Haramaya & 121 & $22(18.2)$ & 1.00 (ref.) & 1.00 (ref.) & - \\
\hline & Gursum & 176 & $61(34.7)$ & $2.39(1.37-4.16)$ & $0.52(0.20-1.36)$ & 0.185 \\
\hline & Babille & 113 & $30(26.6)$ & $1.63(0.87-3.03)$ & $0.15(0.05-0.48)$ & $<0.001^{*}$ \\
\hline \multirow{2}{*}{ Environment } & Rural & 340 & $79(23.2)$ & 1.00 (ref.) & - & - \\
\hline & Urban & 70 & $34(48.6)$ & $3.12(1.83-5.31)$ & - & - \\
\hline \multirow{2}{*}{ Sex } & Male & 93 & $16(17.2)$ & 1.00 (ref.) & 1.00 (ref.) & - \\
\hline & Female & 317 & $97(30.6)$ & $2.12(1.18-3.82)$ & $1.65(0.86-3.18)$ & 0.134 \\
\hline \multirow{2}{*}{ Age } & $\leq 1$ year & 63 & $6(9.5)$ & 1.00 (ref.) & 1.00 (ref.) & - \\
\hline & $>1$ year & 347 & $107(30.8)$ & $4.24(1.77-10.12)$ & $3.45(1.34-8.90)$ & $0.010^{*}$ \\
\hline \multirow{3}{*}{ Breed } & Hararghe highland & 29 & $5(17.2)$ & 1.00 (ref.) & 1.00 (ref.) & - \\
\hline & Long ear Somali & 349 & $95(27.2)$ & $1.80(0.67-4.84)$ & $1.10(0.36-3.39)$ & 0.863 \\
\hline & Undetermined & 32 & $13(40.6)$ & $3.28(0.99-10.84)$ & $2.77(0.68-11.31)$ & 0.155 \\
\hline \multirow{2}{*}{ Flock size } & Small & 324 & $95(29.3)$ & 1.00 (ref.) & 1.00 (ref.) & - \\
\hline & Large & 86 & $18(20.9)$ & $0.64(0.36-1.13)$ & $0.85(0.45-1.60)$ & 0.607 \\
\hline \multirow{2}{*}{ Cats contact } & No & 270 & $70(25.9)$ & 1.00 (ref.) & - & - \\
\hline & Yes & 140 & $43(30.7)$ & $1.27(0.81-1.99)$ & - & - \\
\hline \multirow{3}{*}{ Water source } & Mixed $^{\dagger}$ & 188 & $29(15.4)$ & 1.00 (ref.) & 1.00 (ref.) & - \\
\hline & Pond $^{\ddagger}$ & 152 & $50(32.9)$ & $2.69(1.60-4.52)$ & $6.03(2.42-15.05)$ & $<0.001^{*}$ \\
\hline & Pipe water & 70 & $34(48.6)$ & $5.18(2.80-9.56)$ & $11.61(4.35-30.95)$ & $<0.001^{*}$ \\
\hline \multirow{3}{*}{ House type } & Pen & 27 & $5(18.5)$ & 1.00 (ref.) & - & - \\
\hline & Both & 292 & $73(25.0)$ & $1.47(0.54-4.01)$ & - & - \\
\hline & Fence & 91 & $35(38.5)$ & $2.75(0.95-7.93)$ & - & - \\
\hline
\end{tabular}

$\operatorname{Mixed}^{\dagger}$ : river, stream water, and well; Pond ${ }^{\ddagger}$ : stagnant water; OR: odds ratio; CI: confidence interval. ${ }^{*}$ Significant.

in those that drank from mixed water sources. In contrast, Babille district $(\mathrm{OR}=0.15,95 \% \mathrm{CI}=0.05-0.48, P<0.001)$ was found to be a lower risk for goats (Table 3). Variables such as sex, breed, and flock size were not found to be significant $(P>0.05)$. However, raised seroprevalence was obtained in females (30.6\%) compared to males (17.2\%) and in small flock size $(29.3 \%)$ compared to large $(20.9 \%)$.

3.1.3. Cattle. Multivariable logistic regression analysis indicated that district, herd size, and water source were risk factors for T. gondii infection. Using pond water $(\mathrm{OR}=5.60$, 95\% CI: $2.12-14.78, P<0.001)$ and pipe water sources (OR $=10.68,95 \%$ CI: $2.23-51.22, P=0.003$ ) had significantly increased the risk of acquiring T. gondii infection compared to using mixed water sources, while living in Gursum district $(\mathrm{OR}=0.19,95 \% \mathrm{CI}: 0.06-0.59, P=0.004)$ and belonging to large herd size (OR $=0.35,95 \% \mathrm{CI}: 0.13-0.97, P=0.044)$ were associated with lower risk (Table 4). Among the variables included in the statistical analysis, cats contact and house types were not significant $(P>0.05)$.

3.1.4. Camels. The sole risk factor identified in camels is age. Camels in the age group of $>4$ years $(\mathrm{OR}=2.49,95 \%$ CI: 1.14-5.45, $P=0.022$ ) showed an increased risk of $T$. gondii infection than those $\leq 4$ years (Table 5). Although not statistically significant, difference seen $(P>0.05)$ in $T$. gondii infection in camels having contact with cats (21.7\%) was higher than that seen in those not having contact (13.0\%).

\section{Discussion}

The present study had given an insight on toxoplasmosis and revealed the widespread occurrence of $T$. gondii infection among the domestic ruminants raised in East Hararghe zone. The observed seroprevalence of T. gondii infection in sheep in this study is in agreement with those previously reported from Ethiopia, 31.59\% from East and West Shewa Zones of Oromia Region [15] and 34\% in Debre Birhan [17], and from elsewhere in the world, $29.41 \%$ and $32.9 \%$ from Brazil [5, 23] and $27.6 \%$ from Morocco [9]. But the current prevalence is slightly higher than the prevalence from central Ethiopia, $22.9 \%$ [16], Nigeria, 6.7\% [10], Pakistan, 11.1\% [24], and northeastern China, 3.0\% [25], while it is lower than the seroprevalence of $52.6 \%$ using MDAT and 56\% with ELISA from Nazareth, Ethiopia [19].

In goats, the percentage of $T$. gondii infection is in consistence with the reported prevalence of $24.1 \%$ using MDAT and $25.9 \%$ by ELISA in Nazareth, Ethiopia [18], and $27.9 \%$ in Thailand [26] and higher than $11.6 \%$ [16] and $15.48 \%$ [27] in Central Ethiopia. However, on the contrary, it was lower than the reported prevalence of $35 \%$ in Debre Berhan, Ethiopia [16], and 44.3\% in Egypt [28].

The seroprevalence of $T$. gondii infection in cattle observed in this study is comparable with the reported seroprevalence of $6.6 \%$ from Central Ethiopia [16], 15.77\% in Iran [29], and 13\% in Tanzania [11]. However, the current value is higher than the reported seroprevalence of $2.68 \%$ in Brazil [30] and 3.92\% in Algeria [31]. In contrast, it is 
TABLE 4: Logistic regression analysis of risk factors with T. gondii seropositivity in cattle at animal level $(n=326)$.

\begin{tabular}{|c|c|c|c|c|c|c|}
\hline Variables & Category & Number tested & Positive (\%) & Crude OR $(95 \% \mathrm{CI})$ & Adjusted OR (95\% CI) & $P$ value \\
\hline \multirow{3}{*}{ District } & Haramaya & 87 & $14(16.1)$ & 1.00 (ref.) & 1.00 (ref.) & - \\
\hline & Gursum & 153 & $9(5.9)$ & $0.33(0.13-0.79)$ & $0.19(0.06-0.59)$ & $0.004^{*}$ \\
\hline & Babille & 86 & $12(14.0)$ & $0.85(0.37-1.95)$ & $1.60(0.49-5.16)$ & 0.434 \\
\hline \multirow{2}{*}{ Environment } & Rural & 303 & $30(9.9)$ & 1.00 (ref.) & - & \\
\hline & Urban & 23 & $5(21.7)$ & $2.53(0.88-7.30)$ & - & \\
\hline \multirow{2}{*}{ Sex } & Male & 97 & $11(11.3)$ & 1.00 (ref.) & - & \\
\hline & Female & 229 & $24(10.5)$ & $0.92(0.43-1.95)$ & - & \\
\hline \multirow{3}{*}{ Age } & $\leq 1$ year & 34 & $3(8.8)$ & 1.00 (ref.) & - & \\
\hline & $>1-5$ years & 186 & $19(10.2)$ & $1.18(0.33-4.21)$ & - & \\
\hline & $>5$ years & 106 & $13(12.3)$ & $1.44(0.39-5.40)$ & - & \\
\hline \multirow{2}{*}{ Herd size } & Small & 218 & $27(12.4)$ & 1.00 (ref.) & 1.00 (ref.) & - \\
\hline & Large & 108 & $8(7.4)$ & $0.57(0.25-1.29)$ & $0.35(0.13-0.97)$ & $0.044^{*}$ \\
\hline \multirow{2}{*}{ Cats contact } & No & 223 & $19(8.5)$ & 1.00 (ref.) & 1.00 (ref.) & - \\
\hline & Yes & 103 & $16(15.5)$ & $1.97(0.97-4.02)$ & $2.23(0.86-5.77)$ & 0.097 \\
\hline \multirow{3}{*}{ Water source } & Mixed $^{\dagger}$ & 234 & $14(6.0)$ & 1.00 (ref.) & 1.00 (ref.) & - \\
\hline & Pond ${ }^{\ddagger}$ & 69 & $16(23.2)$ & $4.75(2.18-10.32)$ & $5.60(2.12-14.78)$ & $<0.001^{*}$ \\
\hline & Pipe water & 23 & $5(21.7)$ & $4.37(1.41-13.49)$ & $10.68(2.23-51.22)$ & $0.003^{*}$ \\
\hline \multirow{3}{*}{ House type } & Barn & 29 & $5(17.2)$ & 1.00 (ref.) & 1.00 (ref.) & - \\
\hline & Both & 246 & $23(9.4)$ & $0.50(0.17-1.42)$ & $0.23(0.05-0.99)$ & 0.049 \\
\hline & Fence & 51 & $7(13.7)$ & $0.76(0.22-2.67)$ & $0.42(0.08-2.32)$ & 0.318 \\
\hline
\end{tabular}

$\operatorname{Mixed}^{\dagger}$ : river, stream water, and well; Pond ${ }^{\ddagger}$ : stagnant water; OR: odds ratio; CI: confidence interval. * Significant.

TABLE 5: Analysis of risk factors with T. gondii seropositivity in camels at animal level $(n=292)$.

\begin{tabular}{|c|c|c|c|c|c|c|}
\hline Variables & Category & Number tested & Positive (\%) & Crude OR $(95 \%$ CI $)$ & Adjusted OR (95\% CI) & $P$ value \\
\hline \multirow{2}{*}{ District } & Gursum & 95 & $13(13.7)$ & 1.00 (ref.) & - & - \\
\hline & Babille & 197 & $29(14.7)$ & $1.09(0.54-2.20)$ & - & - \\
\hline \multirow{2}{*}{ Sex } & Male & 73 & $11(15.1)$ & 1.00 (ref.) & - & - \\
\hline & Female & 219 & $31(14.2)$ & $0.93(0.44-1.96)$ & - & - \\
\hline \multirow{2}{*}{ Age } & $\leq 4$ years & 110 & $9(8.2)$ & 1.00 (ref.) & 1.00 (ref.) & - \\
\hline & $>4$ years & 182 & $33(18.1)$ & $2.49(1.14-5.42)$ & $2.49(1.14-5.45)$ & $0.022^{*}$ \\
\hline \multirow{2}{*}{ Herd size } & Small & 203 & $30(14.8)$ & 1.00 (ref.) & - & - \\
\hline & Large & 89 & $12(13.5)$ & $0.90(0.44-1.85)$ & - & - \\
\hline \multirow{2}{*}{ Cat contact } & No & 246 & $32(13.0)$ & 1.00 (ref.) & 1.00 (ref.) & - \\
\hline & Yes & 46 & $10(21.7)$ & $1.86(0.84-4.10)$ & $1.87(0.84-4.18)$ & 0.127 \\
\hline \multirow{2}{*}{ Water source } & Mixed $^{\dagger}$ & 215 & $30(14.0)$ & 1.00 (ref.) & - & - \\
\hline & Pond ${ }^{\ddagger}$ & 77 & $12(15.6)$ & $1.14(0.55-2.35)$ & - & - \\
\hline
\end{tabular}

Mixed $^{\dagger}$ : river, stream water, and well; Pond ${ }^{\ddagger}$ : stagnant water; OR: odds ratio; CI: confidence interval. ${ }^{*}$ Significant.

lower than that of the determined seroprevalence of $22.3 \%$ in Thailand [32], 32\% in Sudan [12], and 43.5\% in Pakistan [33].

In the present study, the proportion of camels positive for anti-T. gondii antibodies (14.4\%) at animal level is in consistence with the proportion in Sudan (20\%) [12], while it is higher than that of $3 \%$ in China [34].

The flock/herd level seroprevalence in sheep, goats, cattle, and camels in the current study was high. The flock seroprevalence recorded in sheep is like that of the previously reported value of $70.48 \%$ in East and West Shewa zones of Oromia Region, Ethiopia [15], and 58.89\% in Algeria [31]. In goats, the flock seroprevalence was higher than that of $45.17 \%$ reported by Swai and Kaaya [13] in Tanzania. The variation in seroprevalence of T. gondii infection among domestic ruminants in the current study from those previously reported in Ethiopia and elsewhere in the world might be attributed to differences in geographical location, animal management practices, and the sensitivity and specificity of serological diagnostic tests used for detecting the infection.

In this study, a significant difference in T. gondii seropositivity was observed between the two sex groups of sheep. Female sheep were 2.63 times more infected than males and those that drank from pond and pipe water sources were 4.25 and 9.57 times more infected than those that drank from mixed water sources, respectively. This finding was in accordance with that reported by Ramzan et al. [24]. The 
increased susceptibility of females might be associated with their lower immunologic resistance in certain periods of their lives [35]. In contrast, Silva et al. [36] and Lashari and Tasawar [37] observed that higher seroprevalence in male sheep than in females is attributed to androgen production lowering their immunity.

In goats, those $>1$ year old were 3.45 times more infected than those $\leq 1$ year old. Besides, goats that drank pond and pipe water had 6.03 times and 11.61 times more chance of acquisition of $T$. gondii infection, respectively. Likewise, cattle that obtained drinking water from ponds and pipes were 5.60 and 10.68 times more infected with T. gondii compared with those that used other water sources. Camels $>4$ years old were 2.49 times more infected compared with those $\leq 4$ years old.

The progressive increase in seroprevalence with age seen in sheep, goat, cattle, and camel indicates sustained exposure to the $T$. gondii infection in the environment $[6,19]$. Moreover, in the present study, a significantly higher T. gondii infection was found in goats $>1$ year old and camel $>4$ years old compared with the remaining age groups. This may be due to the fact that animals that lived longer might be more likely exposed to the infectious agent from different sources $[19,26]$.

The observed increased risk of infection in sheep, goats, and cattle that were given pipe water might be explained by the presence of several roaming cats capable of contaminating the pipe water source with infective $T$. gondii oocysts. Silva et al. [36] and Tenter [38] suggested that few cats are sufficient to contaminate a wide field area in short time, since one infected cat sheds millions of oocysts. In addition, watering troughs and the storage of animal feeds stored outdoor which are accessible to cats might be contributed to the heightened seropositivity of T. gondii infection among domestic ruminants.

Consistent with the present finding, Gebremedhin et al. [15] reported high risk of infection in sheep given pipe water. However, contrary to our finding, Pinheiro et al. [5] observed increased chances of infection in animals living on properties with running water systems than those living with stagnant water sources. The similarities and differences might be attributed to the resemblance and variations in agroecological situation and rate of contamination of the water properties by infective oocysts.

\section{Conclusion}

It could be concluded that $T$. gondii infection is more common and widespread among domestic ruminants found in the study area. Sex, age, and water source act as risk factors for T. gondii infection. Thus, the higher seroprevalence encountered in these animal species used as a food source revealed the potential risk of $T$. gondii infection presented to people through consumption of their meat. Therefore, awareness of people on ways of transmission and prevention of $T$. gondii infection should be raised through education and further study should be conducted to explore the impact of the disease on food animal production.

\section{Conflicts of Interest}

The authors declare that there are no conflicts of interest.

\section{Acknowledgments}

The financial support of Addis Ababa University and EthioItalian project is highly acknowledged. The authors acknowledge the National Animal Health and Disease Investigation Center at Sebeta for availing their laboratory facilities. The authors also would like to extend their gratefulness to the veterinary professionals in the study areas for their collaboration in this study.

\section{References}

[1] J. P. Dubey, Toxoplasmosis of animals and humans, CRC Press, 2nd edition, 2010.

[2] E. Bártová, K. Sedlák, and I. Literák, "Toxoplasma gondii and Neospora caninum antibodies in sheep in the Czech Republic," Veterinary Parasitology, vol. 161, no. 1-2, pp. 131-132, 2009.

[3] A. M. Tenter, A. R. Heckeroth, and L. M. Weiss, "Toxoplasma gondii: from animals to humans," International Journal for Parasitology, vol. 30, no. 12-13, pp. 1217-1258, 2000.

[4] D. Buxton and B. Lesson, "Toxoplasmosis: general considerations," in Protozoal abortion in farm ruminants: guideline for diagnosis and control, M. L. Ortega-Mora, B. Gottstein, F. J. Conraths, D. Buxton, and U. K. Reading, Eds., pp. 122-171, CAB International, 2007.

[5] J. W. Pinheiro Jr., R. A. Mota, A. A. Da Fonseca Oliveira et al., "Prevalence and risk factors associated to infection by Toxoplasma gondii in ovine in the State of Alagoas, Brazil," Parasitology Research, vol. 105, no. 3, pp. 709-715, 2009.

[6] M. Sharif, S. Gholami, H. Ziaei et al., "Seroprevalence of Toxoplasma gondii in cattle, sheep and goats slaughtered for food in Mazandaran province, Iran, during 2005," The Veterinary Journal, vol. 174, no. 2, pp. 422-424, 2007.

[7] A. C. A. V. Carneiro, M. Carneiro, A. M. G. Gouveia et al., "Seroprevalence and risk factors of caprine toxoplasmosis in Minas Gerais, Brazil," Veterinary Parasitology, vol. 160, no. 3-4, pp. 225-229, 2009.

[8] S. Hall, M. Ryan, and M. Buxton, "The epidemiology of toxoplasma infection," in Toxoplasmosis, a Comprehensive Clinical Guide, D. H. M. Joynson and T. G. Wreghitt, Eds., pp. 58-124, Cambridg Univrsity Prss, 2001.

[9] P. Sawadogo, J. Hafid, B. Bellete et al., "Seroprevalence of T. gondii in sheep from Marrakech, Morocco," Veterinary Parasitology, vol. 130, no. 1-2, pp. 89-92, 2005.

[10] J. Kamani, A. U. Mani, and G. O. Egwu, "Seroprevalence of Toxoplasma gondii infection in domestic sheep and goats in Borno state, Nigeria," Tropical Animal Health and Production, vol. 42, no. 4, pp. 793-797, 2010.

[11] L. B. Schoonman, T. Wilsmore, and E. S. Swai, "Seroepidemiological investigation of bovine toxoplasmosis in traditional and smallholder cattle production systems of Tanga Region, Tanzania," Tropical Animal Health and Production, vol. 42, no. 4, pp. 579-587, 2010.

[12] M. K. Khalil and E. I. Elrayah, "Seroprevalence of Toxoplasma gondii antibodies in farm animals (camels, cattle, and sheep) in Sudan," Journal of Medicine and Animal Health, vol. 3, no. 3, pp. 36-39, 2011. 
[13] E. S. Swai and J. E. Kaaya, "A survey of Toxoplasma gondii antibodies by latex agglutination assay in dairy goats in Northern Tanzania.," Tropical Animal Health and Production, vol. 45, no. 1, pp. 211-217, 2012.

[14] CSA, "Agricultural sample Survey 2013/14 [2006 E.C.]. Volume II. Report on livestock and livestock characteristics (private peasant holdings)," Statstical Bulletin 573, Federal democratic republic of Ethiopia Central Statistical Agency (CSA), Addis Ababa, Ethiopia, 2014.

[15] E. Z. Gebremedhin, A. Agonafir, T. S. Tessema et al., "Seroepidemiological study of ovine toxoplasmosis in East and West Shewa Zones of Oromia Regional State, Central Ethiopia," BMC Veterinary Research, vol. 9, article 117, 2013.

[16] T. Bekele and O. B. Kasali, "Toxoplasmosis in sheep, goats and cattle in central Ethiopia," Veterinary Research Communications, vol. 13, no. 5, pp. 371-375, 1989.

[17] T. Demissie and G. Tilahun, "Study on toxoplasmosis in sheep and goats in Debre Birhan and the surrounding areas in Ethiopa," Bulletin of Animal Health and Production in Africa, vol. 50, pp. 138-147, 2002.

[18] T. Negash, G. Tilahun, S. Patton, F. Prévot, and P. H. Dorchies, "Serological survey on Toxoplasmosis in sheep and goats in Nazareth, Ethiopia," Revue de Médecine Vétérinaire, vol. 155, no. 10, pp. 486-487, 2004.

[19] S. Teshale, A. Dumetre, M. L. Darde, B. Merger, and P. Dorchies, "Study on Toxoplasmosis in sheep and goats in Debre Birhan and surrounding areas in Ethiopia," Bull. Animal Health. Production Africa, vol. 50, pp. 138-147, 2007.

[20] E. Zewdu, A. Agonafir, T. S. Tessema et al., "Seroepidemiological study of caprine toxoplasmosis in East and West Shewa Zones, Oromia Regional State, Central Ethiopia," Research in Veterinary Science, vol. 94, no. 1, pp. 43-48, 2013.

[21] MOAEH, Ministry of Agriculture, East Hararghe Zone Annual report, 2014.

[22] M. Thrusfield, Veterinary Epidemiology, Blackwell science Ltd., 3rd edition, 2005.

[23] M. M. Clementino, M. F. Souza, and V. F. A. Neto, "Seroprevalence and Toxoplasma gondii-IgG avidity in sheep from Lajes, Brazil," Veterinary Parasitology, vol. 146, no. 3-4, pp. 199-203, 2007.

[24] M. Ramzan, M. Akhtar, F. Muhammad et al., "Seroprevalence of Toxoplasma gondii in sheep and goats in Rahim Yar Khan (Punjab), Pakistan," Tropical Animal Health and Production, vol. 41, no. 7, pp. 1225-1229, 2009.

[25] C. R. Wang, J. H. Qiu, J. F. Gao et al., "Seroprevalence of Toxoplasma gondii infection in sheep and goats in northeastern China," Small Ruminant Research, vol. 97, no. 1-3, pp. 130-133, 2011.

[26] S. Jittapalapong, A. Sangvaranond, N. Pinyopanuwat et al., "Seroprevalence of Toxoplasma gondii infection in domestic goats in Satun Province, Thailand," Veterinary Parasitology, vol. 127, no. 1, pp. 17-22, 2005.

[27] E. Z. Gebremedhin, M. Abdurahaman, T. Hadush, and T. S. Tessema, "Seroprevalence and risk factors of Toxoplasma gondii infection in sheep and goats slaughtered for human consumption in Central Ethiopia," BMC Research Notes, vol. 7, no. 1, article no. 696, 2014.

[28] R. M. Shaapan, M. A. Hassanam, and F. A. M. Khahl, "Modified agglutination test for serologic survey of Toxoplasma gndii infection in goats and water buffaloes in Egypt," Research Journal of Parasitology, vol. 5, no. 1, pp. 13-17, 2010.
[29] H. Hamidinejat, M. Ghorbanpour, L. Nabavi, M. R. H. Hajikolaie, and M. H. R. Jalali, "Occurrence of anti-Toxoplasma gondii antibodies in female cattle in south-west of Iran," Tropical Animal Health and Production, vol. 42, no. 5, pp. 899-903, 2010.

[30] H. V. Fajardo, S. D’Ávila, R. R. Bastos et al., "Seroprevalence and risk factors of toxoplasmosis in cattle from extensive and semiintensive rearing systems at Zona da Mata, Minas Gerais state, Southern Brazil," Parasites \& Vectors, vol. 6, no. 1, article 191, 2013.

[31] A. S. Dechicha, F. Bachi, I. Gharbi et al., "Sero-epidemiological survey on toxoplasmosis in cattle, sheep and goats in Algeria," African Journal of Agricultural Research, vol. 10, no. 20, pp. 21132119.

[32] S. Jittapalapong, A. Sangwaranond, T. Inpankaew et al., "Seroprevalence of Toxoplasma gondii infection in dairy cows in Northeastern Thailand," The Southeast Asian Journal of Tropical Medicine and Public Health, vol. 39, supplement 1, pp. 1-5, 2008.

[33] Z. Tasawar, Z. Shafiq, M. H. Lashari, and F. Aziz, "Seroprevalence of Toxoplasma gondii in Cattle, Punjab, Pakistan," Global Veterinaria, vol. 11, no. 5, pp. 681-684, 2013.

[34] M. Wang, Y. H. Wang, P. Meng, Q. Ye, and D. L. Zhang, "Toxoplasma gondii infection in Bactrian camel (Camelus bactrianus) in China," Veterinary Parasitology, vol. 192, no. 1-3, pp. 288-289, 2013.

[35] L. A. Guimarães, R. A. Bezerra, D. d. Rocha, and G. R. Albuquerque, "Prevalence and risk factors associated with antiToxoplasma gondii antibodies in sheep from Bahia state, Brazil," Revista Brasileira de Parasitologia Veterinária, vol. 22, no. 2, pp. 220-224, 2013.

[36] A. V. Silva, E. L. P. Cunha, L. R. Meireles, S. Gottschalk, R. A. Mota, and H. Langoni, "Sheep and goat toxoplasmosis: soroepidemiological study in two regions in the state of Pernambuco," Ciência Rural, vol. 33, pp. 115-119, 2003.

[37] M. H. Lashari and Z. Tasawar, "Seroprevalence of toxoplasmosis in sheep in Southern Punjab," Pakistan Veterinary Journal, vol. 30, no. 2, pp. 91-94, 2010.

[38] A. M. Tenter, "Toxoplasma gondii in animals used for human consumption," Memórias do Instituto Oswaldo Cruz, vol. 104, no. 2, pp. 364-369, 2009. 

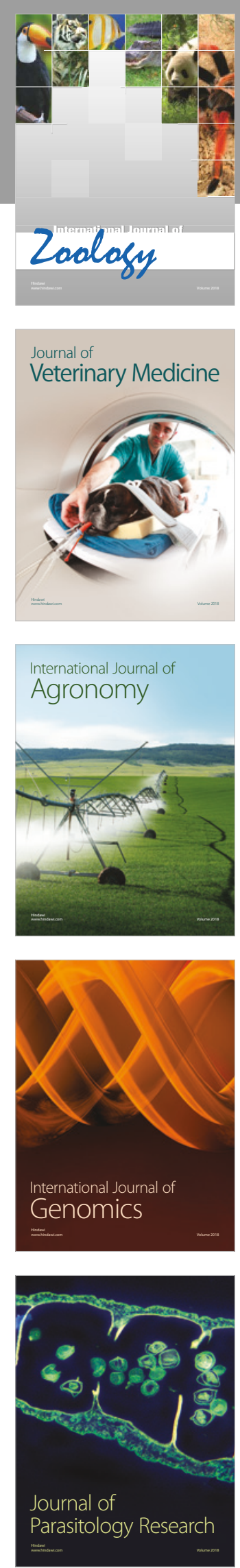

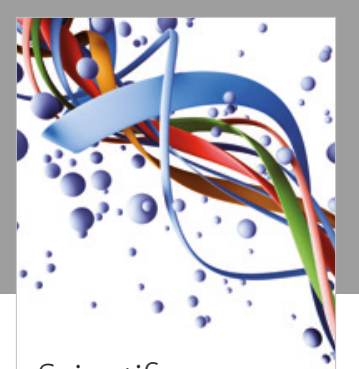

Case Reports in Veterinary Medicine Scientifica
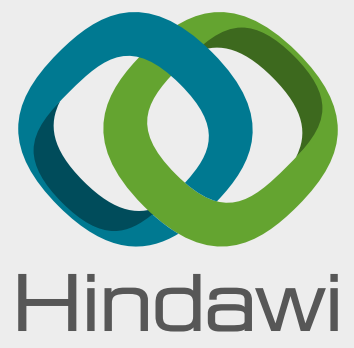

Submit your manuscripts at

www.hindawi.com
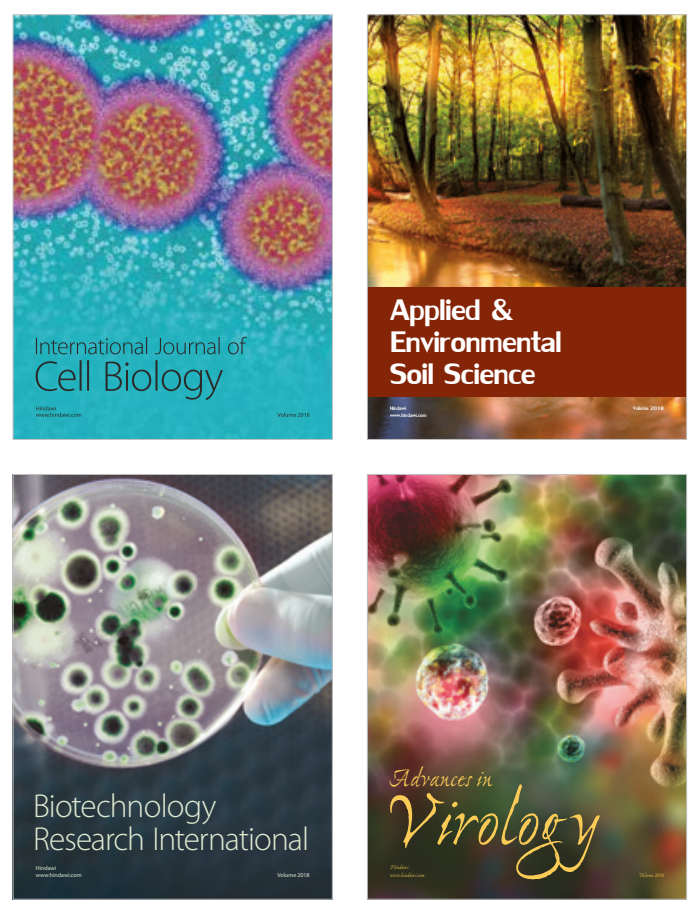

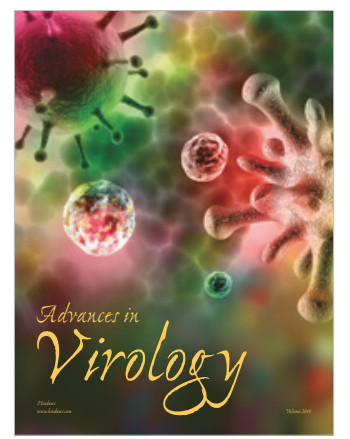

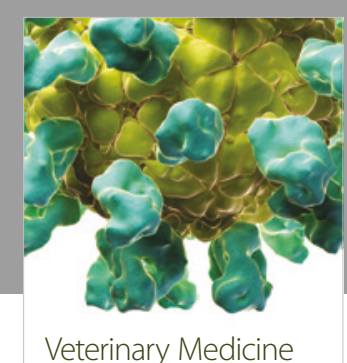
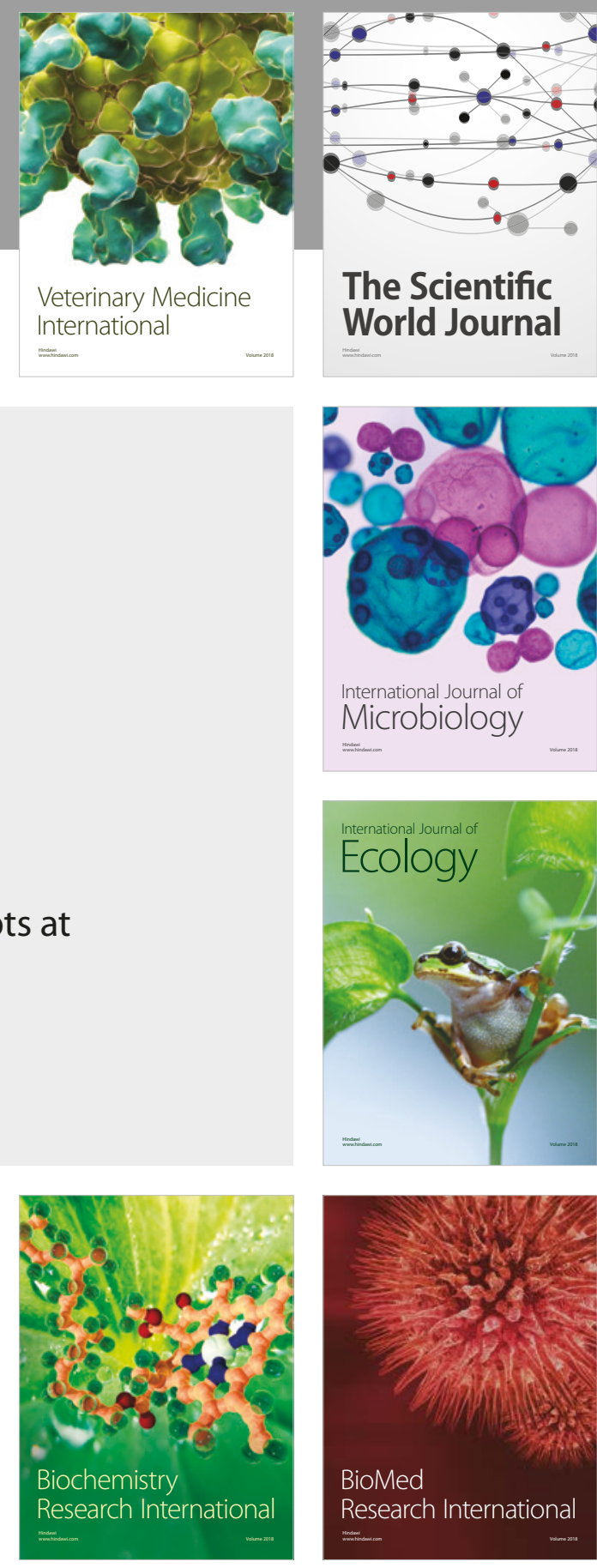

The Scientific World Journal

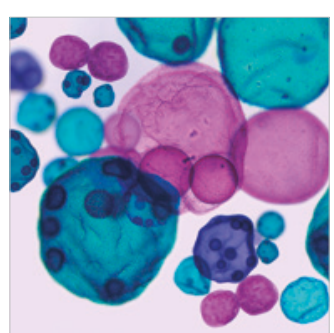

International Journal of Microbiology
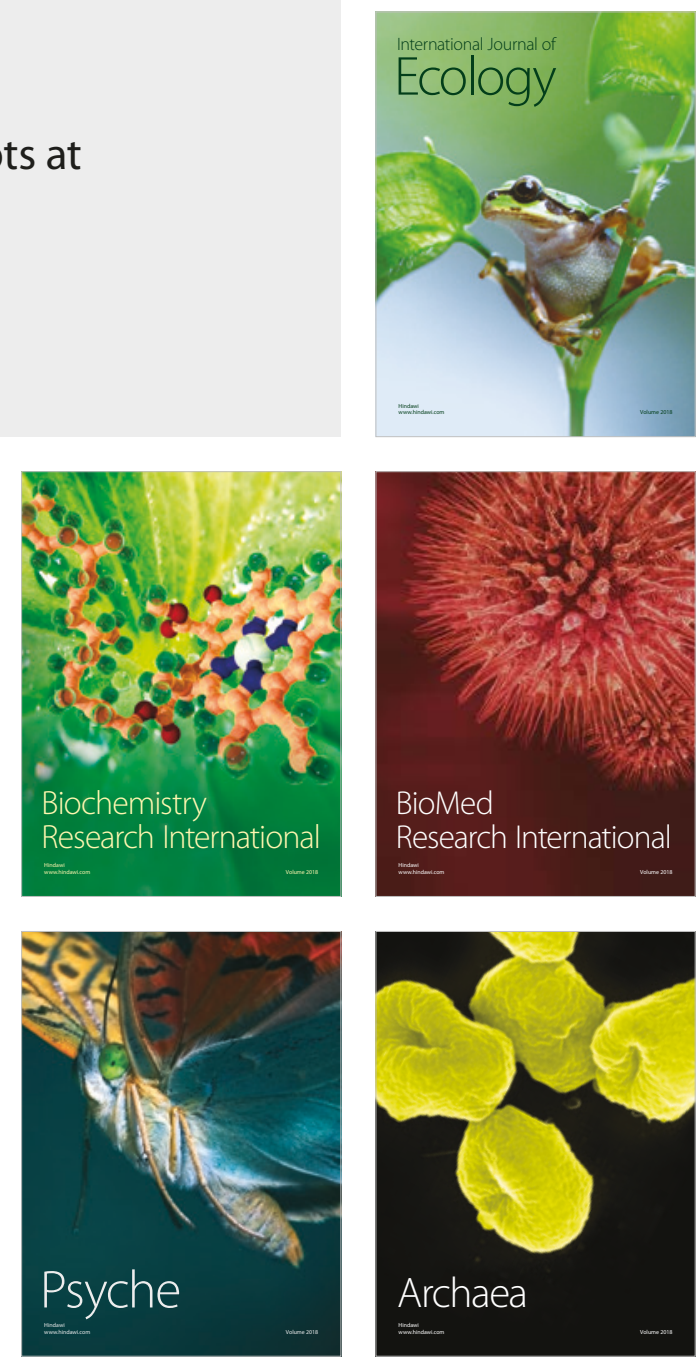